\title{
Exposure assessment to equivalent noise in the coffee production industry
}

\author{
Alexi Delgado, $\mathrm{PhD}^{1}$, Henry Farfan, BSc${ }^{2}$, Jesús Pantoja, BSc${ }^{2}$, Diego Alonso $\mathrm{BSc}^{2}$ and Chiara Carbajal, $\mathrm{BSc}^{3}$ \\ ${ }^{1}$ Pontificia Universidad Católica del Perú, Lima, Peru, kdelgadov@pucp.edu.pe \\ ${ }^{2}$ Universidad Nacional de Ingeniería, Lima, Peru, kdelgadod@uni.edu.pe \\ ${ }^{3}$ Universidad de Ciencias y Humanidades, Lima, Peru, ccarbajal@uch.edu.pe
}

\begin{abstract}
The present article provides the results of a study on the noise as an industrial agent in a coffee company, during the roasting process, packaging and distribution of the final product. The study is oriented to identify the dangers and risks that are presented in the processes to determine the level to which the workers are exposed with the purpose of establishing preventive protection measures that allow to control the risks. Although the results of this study cannot be generalized, due to its qualitative nature, the proposed study can guide similar studies in other related processes in the coffee industry. Agent.

Keywords-- Noise risk, Occupational safety and health, Physical
\end{abstract}

\section{INTRODUCTION}

In Peru, Law No. 29783, the Occupational Safety and Health Law and its Regulations, approved by Supreme Decree No. 005-2012-TR, establishes the employer's obligation to implement the Occupational Safety and Health Management System. This with the purpose of achieve success in preventing occupational incidents, accidents and diseases, depending on the type of company or organization, level of exposure to hazards and risks, and the number of workers exposed [1]. As can be seen in article 56, which establishes that "the employer foresees that exposure to physical, chemical, biological, ergonomic and psychosocial agents concurrent in the workplace do not cause damage to the health of workers" [2]. For this reason, the monitoring of occupational agents is one of the stages of Industrial Hygiene, the objective of which is to avoid occupational diseases, understanding occupational disease as the discomfort or damage to health caused by the presence of pollutants in the work environment to which workers are exposed during the working day [3].

In order to carry out the monitoring, the study has been performed in conjunction with the Peruvian Technical Standard: NTP - ISO 9612: 2010. Due to the fact that this standard establishes an engineering method that allows measuring the exposure to noise of workers in a work environment and calculating the level of exposure to noise [4]. It is highlighted that this method was selected because it is a very useful method when it is required to determine the exposure to noise with engineering degree [5].

The case study selected for this research is the coffee and chocolate producer Britt Brands, since coffee sales in Peru allow the sustainability of thousands of families in the Peruvian

Digital Object Identifier (DOI):

http://dx.doi.org/10.18687/LACCEI2020.1.1.523

ISBN: 978-958-52071-4-1 ISSN: 2414-6390 jungle, as well as contributing nearly $90 \%$ of our Gross Domestic Product (GDP) [6]. In addition, it should be noted that Peru represents $15 \%$ of total sales in a distribution context shared by Brazil, Colombia, Costa Rica, Chile, among others [7].

Thus, since noise, as a physical environmental agent generated from vibrations generated by shocks between two bodies, can generate hearing problems that cause hearing impairment if the phenomenon is performed at high-pressure levels [8]. The specific agent of noise was analyzed to establish the effectiveness of the classical methodology that corresponds to law and regulation; obtaining an overall assessment of the specific risk according to the methodology indicated that allows us to classify in scales of levels of: Very bad, bad, good and very good in each area [9].

The present work is organized as follows: in Section II, the methodology is described. It is followed by Section III, where the case study is presented. Then, the results and discussion are shown in section IV; and finally, section $\mathrm{V}$ shows the conclusions.

\section{METHODOLOGY}

For the present, the Peruvian Technical Standard: NTPISO-9612:2010 "Acoustics. Determination of exposure to occupational noise" [4] is considered for the purpose of:

- Identify the positions to be evaluated.

- Characterize work centers.

- Communicate measurement objectives to staff and headquarters.

This methodology requires the observation and analysis of noise exposure conditions so that the quality of the measurements can be controlled. It also provides methods for estimating the uncertainty of the results.

The results of measurements made according to this Peruvian Technical Standard can provide useful information when defining priorities for noise control measures. The steps taken are as follows:

- The areas for the qualitative determination of the workers who participated in the monitoring were recognized.

- $\quad$ Measurement equipment was installed in the selected workers.

18th LACCEI International Multi-Conference for Engineering, Education, and Technology: "Engineering, Integration, and Alliances for a 
- Physical agents were monitored and evaluated according to established methods.

\section{A. Evaluation criteria}

The following aspects were taken into account when monitoring noise dosimetry in the field:

- The microphone was placed in the middle of the worker's shoulder, and the noise data processing unit was set in a position that did not interfere with the worker's normal activities.

- Measurements were taken during his working day.

- The noise level considered is the resulting equivalent level, which is compared to the allowable reference levels.

- Once the measuring instrument is in place, the equipment is run.

\section{B. Measurement Parameters}

These are the parameters necessary to perform appropriate calculations with the applicable methodologies according to the type of agent. Table I details the parameter according to the agent measured.

TABLE I

MEASUREMENT PARAMETERS

\begin{tabular}{|c|c|c|c|}
\hline $\mathbf{N}^{\circ}$ & Type of agent & Parameter & Unity \\
\hline 1 & Noise Dosimetry & Equivalent Noise Level (A) & $\mathrm{dB}$ \\
\hline
\end{tabular}

Therefore, the Dosimetry would become the long version, to check the variations over a given time (a day or a week). As its name indicates, Dosimetry is used to value a Dose, which is always the result of the quantity (Noise Level) by exposure time. If the noise is present throughout the entire working day (eight hours a day), a complete measurement (eight hours) must be made. The measurement time may be shorter, as long as it is duly justified and the precise sampling time is recorded. The value used in this study is the Weighted Sound Pressure Level (LpA) [10].

\section{Measuring Instrument}

For the measurement of the noise agent, the Larson Davis Noise Dosimeter was used, the technical specifications of which are detailed below:

Airtight equipment with metal housing, no controls or damaging display, the Spark 705+ model is programmed to start automatically and collect noise exposure data discreetly, again and again, is intrinsically safe, is in compliance with ANSI S1.4- 1983, ANSI S1.25 - 1991, IEC60651-1993, IEC 608041993, IEC 61252-1993 standards.

It possesses the following characteristics:

- Measuring range: 40 to $143 \mathrm{~dB}$ (RMS) 80 to $146 \mathrm{~dB}$ (peak) typical

- Maximum Level: 146 dB SPL
- Detectors: slow, fast and peak

- Frequency weighting: A, C unweighted (peak)

Finally, the variety of the model is shown in Table II.

TABLE II

EQUIPMENT DIVERSITY

\begin{tabular}{|c|c|c|c|}
\hline Equipment & Model & Brand & Serial \\
\hline Dosimeter & Larson Davis & Spark 705 & 41434 \\
\hline Dosimeter & Larson Davis & Spark 705 & 41193 \\
\hline Dosimeter & Larson Davis & Spark 705 & 41433 \\
\hline Dosimeter & Larson Davis & Spark 705 & 41435 \\
\hline
\end{tabular}

The Noise Exposure Limit Values are defined considering the time of exposure to industrial noise, in accordance with the following criterion [11]:

TABLE III

EXPOSURE TIME CRITERION

\begin{tabular}{|c|c|}
\hline Time (Hours) & Noise Level dB \\
\hline 24 & 80 \\
\hline 16 & 82 \\
\hline 12 & 83 \\
\hline 8 & 85 \\
\hline 4 & 88 \\
\hline 2 & 91 \\
\hline 1 & 94 \\
\hline
\end{tabular}

Source: R.M. N ${ }^{\circ}$ 375-2008-TR, Basic Standard of Ergonomics and Procedure for Disergonomic Risk Assessment [12].

The noise dose is defined according to (1) [12].

$D=\frac{C_{1}}{T_{1}}+\frac{C_{2}}{T_{2}}+\frac{C_{3}}{T_{3}}+\cdots \frac{C_{n}}{T_{n}}$

Where:

$D$ : Noise dose.

$C_{n}$ : Number of hours of exposure to the equivalent level i.

$T_{n}$ : Number of hours permitted at equivalent level $i(L-$ $85) / 3$.

$T_{n}$ : Number of permissible hours at equivalent level $i$.

$L$ : Equivalent noise level.

With respect to the calculation of intermediate values of the maximum permissible limit, (2) is applied [13].

$$
T=\frac{8}{2^{(L-85) / 3}}
$$

Where:

$T$ : The length of time a worker has been exposed to the equivalent $\mathrm{L}$ level. 
$L:$ It is the equivalent level of noise in decibels in the weighting scale; in other words, it is the noise level in $\mathrm{dB}$ on the "A" weighting scale (dBA) for which you want to know your maximum exposure time.

Replacing the formula to find the equivalent level of noise, for an exposure time of 9.5 hours, the result is as follows:

$$
9.5=\frac{8}{2^{(L-85) / 3}}
$$

Where:

$$
x=84.25 d B \approx 84 d B
$$

Therefore, the maximum permissible limit for an exposure time of 9.5 hours is shown in Table IV.

TABLE IV

MAXIMUM ALLOWABLE LIMIT VALUE

\begin{tabular}{|c|c|}
\hline Maximum Noise Level & $\begin{array}{c}\text { Maximum exposure time of } \\
\text { entire workday }\end{array}$ \\
\hline $84 \mathrm{~dB}$ & 9.5 hours per day \\
\hline
\end{tabular}

Taking into account that the Action Level is $50 \%$ of the dose of the Maximum Allowable Limit, (4) of the noise dose will be applied, having an equivalent noise level "L" in T hours in dBA [13].

$$
50 \%=\frac{T}{8} x 2^{(L-85) / 3}
$$

Where:

$T$ : It is the time that the worker was exposed to the equivalent level $\mathrm{L}$.

$L:$ It is the equivalent level of noise in $\mathrm{dB}$ for $50 \%$ of the dose in time $\mathrm{T}$.

Following the previous exercise, it is replaced in the formula to find the Noise Action Level, for an exposure time of 9.5 hours; the result is as follows:

$$
50 \%=\frac{9.5}{8} \times 2^{(L-85) / 3}
$$

Where:

$$
L=81.25 \quad d B \approx 81 d B
$$

Thus, the action level for an exposure time of 9.5 hours is shown in Table V.

TABLE V

VALUE OF THE MAXIMUM ALLOWABLE LIMIT AND LEVEL OF ACTION

\begin{tabular}{|c|c|c|}
\hline $\begin{array}{c}\text { Maximum Noise } \\
\text { Level }\end{array}$ & Action Level & $\begin{array}{c}\text { Maximum exposure } \\
\text { time of entire } \\
\text { workday }\end{array}$ \\
\hline $84 \mathrm{~dB}$ & $81 \mathrm{~dB}$ & 9.5 hours per day \\
\hline
\end{tabular}

\section{Risk Categorization}

The following exposure categories are established taking as references the Action Level and the maximum permissible limit as it is shown in Table VI.
TABLE VI

CLASSIFICATION CRITERIA FOR EXPOSURE RISK LEVELS

\begin{tabular}{|c|l|}
\hline Level of Exposure & \multicolumn{1}{c|}{ Interpretation } \\
\hline Low & Lower Exposure at Action Level \\
\hline Medium & $\begin{array}{l}\text { Exposure greater than or equal to the Action } \\
\text { Level and less than the Maximum Allowable } \\
\text { Limit }\end{array}$ \\
\hline High & $\begin{array}{l}\text { Exposure greater than or equal to the Maximum } \\
\text { Allowable Limit }\end{array}$ \\
\hline
\end{tabular}

\section{E. Hearing Aid Attenuation}

There are various methods to calculate the attenuation provided by a hearing protector, the choice of which will be determined by the information available from both the noise in the working environment and the hearing protector. Each method provides an estimate of attenuation, the more accurate the more complete the information available.

\section{1) NRR Method}

For this method, the C-weighted sound pressure level and the NNR parameter of the hearing protector must be specified. The A-weighted attenuated sound pressure level is calculated using (6) [14].

$$
N P S e q \text { attenuated }(A)=\operatorname{Leq} C-N R R
$$

If the level of noise exposure, as measured by the application of the A-weighted scale, is known, it is calculated using (7) [14].

$$
N P S e q \text { attenuated }(A)=\text { Leq } A-(N R R-7)
$$

When it is necessary, due to the aggressiveness of the sound environment, to use double hearing protection (earplugs and earmuffs), in this case the one with the highest noise reduction rate (NNR) should be taken to calculate the affective noise level. Equation (8) is applied [14].

$$
N P S e q \text { attenuated }(A)=\operatorname{Leq} A-[(N R R-7)+5]
$$

Where:

Leq $C$ : Sound-pressure equivalent in weight $C$.

Leq $A$ : Sound-pressure equivalent in weight $A$.

$N R R$ : Noise Reduction Ratio

To adjust working conditions, Occupational Safety and Health Administration recommends that a 50\% correction factor should be applied when estimating the attenuation of hearing protectors in the field; therefore, (9) is proposed [14].

$$
N P S e q \text { attenuated }(A)=\text { Leq } A-[(N R R-7) x 50 \%]
$$

And in the instance of the use of two hearing protectors, (10) will be employed [14].

$N P S e q$ attenuated $(A)=\operatorname{Leq} A\{[(N R R-7) x 50 \%]+5\}(10)$ 


\section{CASE STUDY}

The evaluation of this study will be determined by the noise samples collected during the monitoring of different occupational agents performed at Britt Brands, in order to achieve the purpose of the present work, we focused on the sound agent; for which four (04) plant environments of the company were selected, areas such as:

- Chocolate plant

- Confectionery area

- Coffee plant 1

- Coffee plant 2

The field evaluations were carried out during daylight hours, starting the installation of equipment to the workers chosen between 9:00 am and 9:45 am in the areas previously indicated.

The monitoring area can be visualized in Fig. 1 .

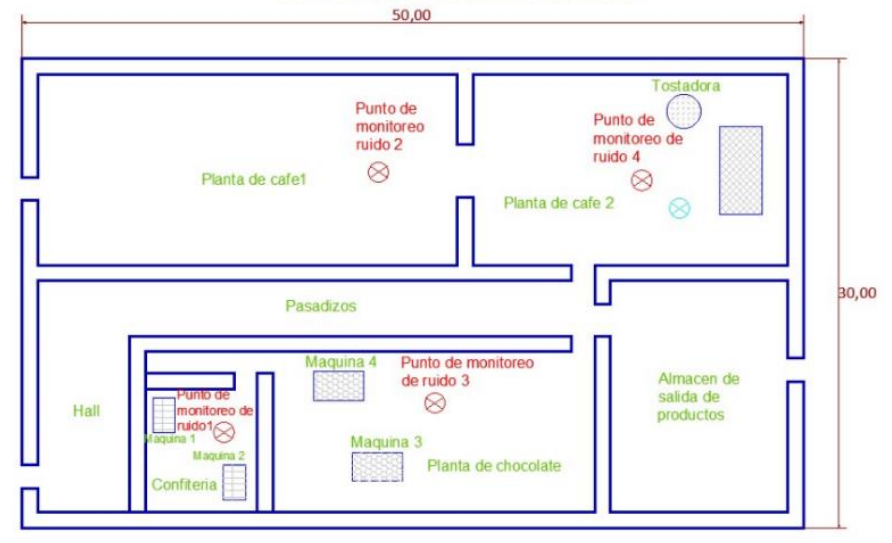

Fig. 1 Monitoring Area.

\section{RESULTS AND DISCUSSION}

The results of the Noise Dosimetry Monitoring can be seen in Table VII.

TABLE VII

NOISE DOSIMETRY MONITORING RESULTS

\begin{tabular}{|c|c|c|c|c|c|c|c|c|}
\hline \multirow[b]{2}{*}{ Code } & \multirow[b]{2}{*}{ Job Title } & \multirow[b]{2}{*}{$\begin{array}{l}\text { Measurement } \\
\text { Period }\end{array}$} & \multicolumn{3}{|c|}{ Noise Pressure Level } & \multirow[b]{2}{*}{$\begin{array}{c}\text { Maximum } \\
\text { Permissible } \\
\text { Limit (in } \mathrm{dB}(\mathrm{A}) \text { ) }\end{array}$} & \multirow[b]{2}{*}{$\begin{array}{l}\text { Action Level } \\
\text { (in dB(A)) }\end{array}$} & \multirow[b]{2}{*}{$\begin{array}{c}\text { Exposure } \\
\text { Level }\end{array}$} \\
\hline & & & $\begin{array}{l}\text { Maximum } \\
\text { Noise } \\
\text { Pressure } \\
\text { Level } \\
\end{array}$ & $\begin{array}{l}\text { Minimum } \\
\text { Noise } \\
\text { Pressure } \\
\text { Level } \\
\end{array}$ & $\begin{array}{l}\text { Equivalent } \\
\text { Pressure } \\
\text { Level }\end{array}$ & & & \\
\hline DR-01 & $\begin{array}{l}\text { Production } \\
\text { Operator- } \\
\text { Machinist }\end{array}$ & $8 \mathrm{~h} 17 \mathrm{~min}$ & 52.1 & 89.3 & 80.5 & 84 & 81 & Low \\
\hline DR-02 & $\begin{array}{l}\text { Production } \\
\text { Operator - } \\
\text { Roaster }\end{array}$ & $8 \mathrm{~h} 13 \mathrm{~min}$ & 55.3 & 92 & 83.9 & 84 & 81 & Medium \\
\hline DR-03 & $\begin{array}{l}\text { Production } \\
\text { Operator- } \\
\text { Machinist }\end{array}$ & $8 \mathrm{~h} 46 \mathrm{~min}$ & 54.5 & 89.6 & 81.5 & 84 & 81 & Medium \\
\hline DR-04 & $\begin{array}{l}\text { Production } \\
\text { Operator- } \\
\text { Assistant } \\
\text { Roaster } \\
\end{array}$ & $8 \mathrm{~h} 07 \mathrm{~min}$ & 52.5 & 95 & 83.3 & 84 & 81 & Medium \\
\hline
\end{tabular}

From the results obtained, it can be determined that the four exposed workers (represented by codes from DR-01 to DR-04) are at a low to medium level of exposure. As it is seen, the operators of machinists and roasters' assistants are those who exceed the action level; however, this may be because, due to their same functions and positions, they do not use any type of hearing protectors that protect them from the industrial noise found in the same factory [15].

A more dynamic appreciation can be observed in Fig. 2, where each worker is analyzed and the maximum permissible limit in $\mathrm{dB}(\mathrm{A})$ is delineated with a red line and the action level $\mathrm{dB}(\mathrm{A})$ with a green line [16].

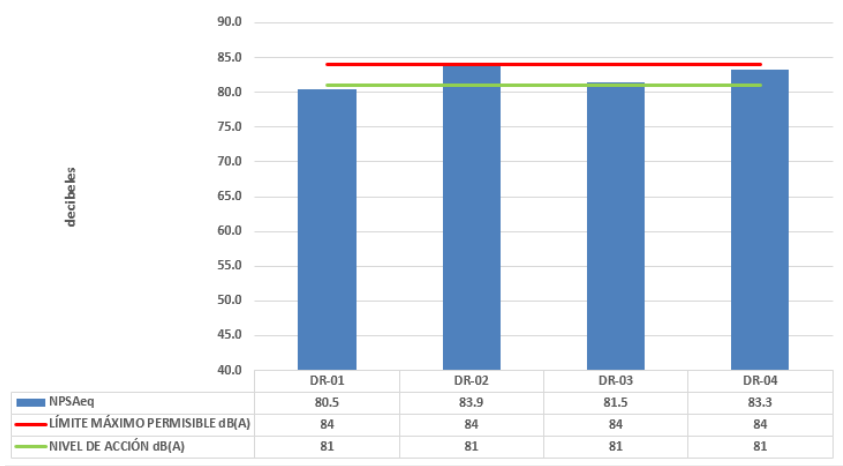

Fig. 2 Job-Based Sound Pressure Level Comparison. 
TABLE VIII

SOUND PRESSURE ATTENUATION BY THE USE OF HEARING PROTECTION AT DOSIMETRY LEVEL

\begin{tabular}{|c|c|c|c|c|c|c|c|}
\hline Code & $\begin{array}{l}\text { Hearing } \\
\text { Protector }\end{array}$ & $\begin{array}{c}\text { Hearing } \\
\text { Protector Noise } \\
\text { Reduction Rate }\end{array}$ & $\begin{array}{c}\text { Equivalent } \\
\text { Pressure Level }\end{array}$ & $\begin{array}{c}\text { Equivalent } \\
\text { Pressure Level } \\
\text { Attenuated }\end{array}$ & $\begin{array}{c}\text { RM-375-2008- } \\
\text { TR }\end{array}$ & $\begin{array}{l}\text { Action Level (in } \\
\mathrm{dB}(\mathrm{A}))\end{array}$ & Exposure Level \\
\hline DR-01 & $\begin{array}{l}\text { STEELPRO } \\
\text { Plugs }\end{array}$ & 32 & 80.5 & 68 & 81 & 84 & Low \\
\hline DR-02 & $\begin{array}{l}\text { STEELPRO } \\
\text { Plugs }\end{array}$ & 32 & 83.9 & 71.4 & 81 & 84 & Low \\
\hline DR-03 & $\begin{array}{l}\text { STEELPRO } \\
\text { Plugs } \\
\end{array}$ & 32 & 81.5 & 69 & 81 & 84 & Low \\
\hline DR-04 & $\begin{array}{c}\text { STEELPRO } \\
\text { Plugs }\end{array}$ & 32 & 83.3 & 70.8 & 81 & 84 & Low \\
\hline
\end{tabular}

On the other hand, the results of the sound pressure attenuation by the use of hearing protectors at Dosimetry level can be found in Table VIII. With this variant of the NRR methodology, it has been obtained that the levels of exposure are low by means of the hearing protectors used by the workers. Following the previous sequence, Fig. 3 shows the comparison of sound pressure level and attenuation of the hearing protector per job, taking as a model the first two workers to be considered [17].

In this case, the indicators that will be taken into account are the results obtained by R.M. $\mathrm{N}^{\circ}$ 375-2008-TR, Basic Standard of Ergonomics and Procedure of Disergonomic Risk Assessment, marked by a red line; and the results with respect to the level of Action $\mathrm{dB}(\mathrm{A})$ delimited by a green line [18].

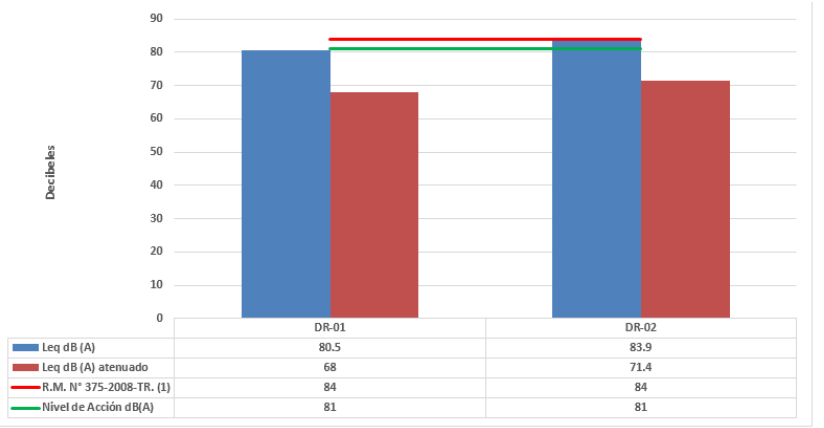

Fig. 3 Sound-pressure level and hearing protector attenuation comparison.

\section{CONCLUSIONS}

The reduction rate of the Hearing Protector was found to be low, so it can be said that workers are exposed to industrial noise as a consequence of the process itself. Likewise, it has been observed that only the use of Personal Protective Equipment (PPE) is used as safety measures, leaving aside the application of safety measures to noise generators.

For this reason, it is recommended to provide hearing protection for all operators and verify its use during the work they perform constantly. As well as to continue with the execution of the periodic occupational medical examinations of the hearing level, and to communicate the results of these evaluations to the workers, with the purpose that they know their state of health and fulfill the medical recommendations. In addition, personnel should be trained in the risks associated with exposure to noise, including: noise and sound, and their differences, permissible limit levels, the importance of occupational medical examinations, damage to health from exposure to noise, risk controls, correct use, maintenance and replacement of hearing protectors.

Finally, it is highly recommended to ensure that the PPE chosen is suitable for the type and duration of the noise; it must also be compatible with other protective equipment; workers must be able to choose appropriate hearing protection so that they can find the most comfortable solution.

\section{REFERENCES}

[1] A. Delgado, J. Maguiña, R. Cabezas, S. Hidalgo, and C. Carbajal, "Integral assessment of risk level in libraries using the grey clustering method," Int. J. Recent Technol. Eng., vol. 8, no. 3, 2019, doi: 10.35940/ijrte.C5695.098319.

[2] El Peruano, "Normas Legales - Ley N²9783," pp. 1-13, 2011.

[3] A. Delgado, D. Vriclizar, and E. Medina, "Artificial intelligence model based on grey systems to assess water quality from Santa river watershed," in Proceedings of the 2017 Electronic Congress, E-CON UNI 2017, 2017, vol. 2018-January, pp. 1-4, doi: 10.1109/ECON.2017.8247310.

[4] Comisión de Normalización y de Fiscalización de Barreras Comerciales No Arancelarias - INDECOPI, Norma Técnica Peruana: NTP-ISO-9612:2010 - Norma Técnica Peruana: NTP-ISO-9612:2010. 2010.

[5] I. Mohammadfam, M. Kamalinia, M. Momeni, R. Golmohammadi, Y. Hamidi, and A. Soltanian, "Evaluation of the Quality of Occupational Health and Safety Management Systems Based on Key Performance Indicators in Certified Organizations," Saf. Health Work, vol. 8, no. 2, pp. 156-161, Jun. 2017, doi: 10.1016/j.shaw.2016.09.001.

[6] S. Domínguez, "Café nuestro de cada día,” El Peruano, 02-Jun-2016.

[7] L. L. Beranek, "Criteria for Noise in Buildings and Communities," in Noise and Vibration Control Engineering: Principles and Applications: Second Edition, Hoboken, NJ, USA: John Wiley \& Sons, Inc., 2007, pp. 887-909.

[8] M. Párraga Velásquez and T. García Zapata, "EL RUIDO Y EL DISEÑO DE UN AMBIENTE ACÚSTICO,” pp. 1-5, 2005.

[9] A. Delgado, A. Aguirre, E. Palomino, and G. Salazar, "Applying triangular whitenization weight functions to assess water quality of main affluents of Rimac river," in Proceedings of the 2017 Electronic Congress, E-CON UNI 2017, 2017, vol. 2018-January, pp. 1-4, doi: 10.1109/ECON.2017.8247308.

[10]C. Li, K. Chen, and X. Xiang, "An integrated framework for effective safety management evaluation: Application of an improved grey clustering measurement," Expert Syst. Appl., vol. 42, no. 13, pp. 5541-5553, Aug. 2015, doi: 10.1016/J.ESWA.2015.02.053.

[11]M. Gómez, J. Jaramillo, Y. Luna, A. Martínez, M. Adelaida, and E. Vásquez, "Ruido Industrial: Efectos en la salud de los trabajadores expuestos(Industrial noise: effects on the health of workers exposed)(De ruído industrial: efeitos sobre a saúde dos trabalhadores expostos) | Gómez Martínez | CES Salud Pública," Salud Pública, vol. 3, no. 2, pp. 174-183, 2012.

[12] Resolución Ministerial, “RM 375-2008-TR. NORMA BÁSICA DE 
ERGONOMÍA Y DE PROCEDIMIENTO DE EVALUACIÓN DE RIESGO DISERGONÓMICO.”pp. 1-32.

[13] Medición De Ruido, "GUIA N 1."

[14] OSHA, "Methods for Estimating HPD Attenuation."

[15]A. Delgado and I. Romero, "Applying the Grey Systems Theory to Assess Social Impact from an Energy Project," in 2018 IEEE XXV International Conference on Electronics, Electrical Engineering and Computing (INTERCON), 2018, pp. 1-4, doi: 10.1109/INTERCON.2018.8526372.

[16] W. Shiqiang, S. Ruixiang, Y. Kun, and W. Yu, "The research of noise induced tympanic membrane perforation in cotton textile industry," in
2008 IEEE International Conference on Industrial Engineering and Engineering Management, IEEM 2008, 2008, pp. 1587-1590, doi: 10.1109/IEEM.2008.4738139.

[17]A. Delgado and H. Flor, "Selection of the best air purifier system to urban houses using AHP," in 2017 CHILEAN Conference on Electrical, Electronics Engineering, Information and Communication Technologies, CHILECON 2017 - Proceedings, 2017, vol. 2017-January, pp. 1-4, doi: 10.1109/CHILECON.2017.8229622.

[18] Agencia Europea para la Seguridad y la Salud en el Trabajo, "Reducción y control del ruido," 2005. 